\title{
A formação colaborativa de professores que ensinam matemática: uma experiência no contexto de atividades remotas
}

\author{
Ernani Martins dos Santos ${ }^{1}$ \\ Luana Cerqueira de Almeida ${ }^{2}$ \\ Rayssa Melo de Oliveira ${ }^{3}$
}

\begin{abstract}
RESUMO
Pesquisas que envolvem colaboração ou análise de grupos colaborativos têm ganhado cada vez mais espaço na área da Educação. Este artigo tem por objetivo analisar práticas colaborativas desenvolvidas num processo formativo online, com 28 professores que ensinam matemática na Educação Básica e que participam de um projeto em rede. A formação foi desenvolvida a partir da metodologia da Espiral RePARe (ReflexãoPlanejamento-Ação-Reflexão). Tendo como base uma abordagem qualitativa, os dados foram coletados a partir das narrativas dos participantes do processo formativo, em encontros síncronos, em uma plataforma digital, por meio de observações diretas e das gravações de áudio e vídeo dos encontros. Os resultados apontam para a constituição de um grupo colaborativo com práticas pautadas na construção de ambientes de discussão, autonomia e respeito mútuo, que permeiam debates sobre a teoria e a prática no ensino de matemática, a partir de um modelo de formação de professores.
\end{abstract}

PALAVRAS-CHAVE: Formação de professores. Desenvolvimento profissional. Compartilhamento de experiências.

\footnotetext{
1 Doutor em Psicologia Cognitiva. Universidade de Pernambuco - UPE, Recife, Pernambuco, Brasil. Orcid: https://orcid.org/0000-0002-3824-986X.E-mail: ernani.santos@upe.br.

${ }^{2}$ Mestre em Educação Matemática. Universidade Estadual de Santa Cruz - UESC, Ilhéus, Bahia, Brasil. Orcid: https://orcid.org/0000-0001-6858-627X. E-mail: luanacqra@gmail.com.

${ }^{3}$ Mestre em Educação. Universidade Federal do Ceará - UFC, Fortaleza, Ceará, Brasil. Orcid: https://orcid.org/00000002-8234-8240. E-mail: rayssamelodeoliveira@gmail.com.
} 
Collaborative training of teachers who teach mathematics: an experience in the context of remote activities

\begin{abstract}
Research involving collaboration or analysis of collaborative groups has been gaining more space in the field of Education. This paper aims to analyze collaborative practices developed in an online training process, with 28 teachers who teach mathematics in Basic Education and who participate in a network project. The training was developed using the Spiral RePARe methodology (Reflection-Planning-Action-Reflection). Based on a qualitative approach, data were collected from the narratives of participants in the training process, in synchronous meetings on a digital platform, through direct observations and audio and video recordings of the meetings. The results point to the constitution of a collaborative group with practices based on the construction of discussion environments, autonomy and mutual respect, which permeate debates on theory and practice in the teaching of mathematics, based on a teacher training model.
\end{abstract}

KEYWORDS: Teacher training. Professional development. Sharing experiences.

La formación colaborativa de los profesores que enseñan matemáticas: una experiencia en el contexto de las actividades a distancia

\title{
RESUMEN
}

La investigación que implica la colaboración o el análisis de grupos colaborativos ha ido ganando más espacio en el ámbito de la Educación. Este artículo tiene como objetivo analizar las prácticas colaborativas desarrolladas en un proceso de formación online, con 28 profesores que imparten matemáticas en Educación Básica y que participan en un proyecto de red. La formación se desarrolló utilizando la metodología Spiral RePARe (Reflexión-Planificación-Acción-Reflexión). Con base en un enfoque cualitativo, se recolectaron datos de las narrativas de los participantes en el proceso de capacitación, en reuniones sincrónicas en una plataforma digital, a través de observaciones directas y grabaciones de audio y video de las reuniones. Los resultados apuntan a la constitución de un grupo colaborativo con prácticas basadas en la construcción de ambientes de discusión, autonomía y respeto mutuo, que 
permean debates teóricos y prácticos en la enseñanza de las matemáticas, basados en un modelo de formación docente.

PALABRAS CLAVE: Formación de profesores. Desarrollo profesional. Compartiendo experiencias.

$$
* * *
$$

\section{Introdução}

Pesquisas que envolvem colaboração ou análise de grupos colaborativos têm ganhado cada vez mais espaço na área da Educação. Isso se deve, muito provavelmente, às mudanças de perspectivas quanto à produção de conhecimento da academia e às práticas educativas, visto que autores têm apontado que o distanciamento entre as teorias da educação e as vivências pedagógicas pouco têm contribuído para mudanças necessárias nas instituições escolares (CRECCI; FIORENTINI, 2018).

A fim de superar a dicotomia teoria e prática/universidade e escola, metodologias investigativas têm sido exploradas de forma a favorecer o desenvolvimento de saberes significativos para a Educação, bem como a formação de professores que reverberem a transformação de práticas educativas. É dentro desse novo panorama investigativo e formativo que se busca o desenvolvimento de pesquisas colaborativas.

Dessa forma, o presente artigo traz uma discussão sobre o conceito de pesquisa colaborativa, baseado na perspectiva de Ibiapina (2008), descrevendo alguns trabalhos norteados na perspectiva desse tipo de investigação, e evidencia características e contribuições de um grupo colaborativo para o desenvolvimento profissional de professores que ensinam matemática. 
O referido grupo é denominado de Rede Educação Matemática Nordeste (REM-NE); constituiu-se a partir da Rede E-Mult ${ }^{4}$ em 2012, através do Programa Observatório da Educação fomentado pela Coordenação de Aperfeiçoamento de Pessoal de Nível Superior - CAPES, e atualmente é composto por 32 pesquisadores de nove universidades brasileiras situadas na Bahia, Ceará, Pernambuco, Rio Grande do Norte e São Paulo; 28 professores da Educação Básica que atuam nos estados da Bahia, Ceará, Rio Grande do Norte e São Paulo e 21 estudantes, sendo: 11 de graduação, 7 de mestrado e 3 de doutorado, todos vinculados às universidades parceiras. Os professores da Educação Básica, que são os sujeitos desta investigação, lecionam nos anos iniciais e finais do Ensino Fundamental de escolas públicas parceiras da REM$\mathrm{NE}$; de formação eles são pedagogos ou licenciados em matemática e atuam, de maneira colaborativa, com a REM-NE, construindo e participando do processo formativo.

O projeto atualmente em desenvolvimento por esse grupo, de onde este artigo se deriva, é financiado pela Fundação Lemann e acompanhado pela Teachers College - Columbia University, tendo como objetivo estabelecer um processo formativo de professores, que visa planejar sequências de ensino que possam ser desenvolvidas, na abordagem de conceitos estatísticos nas aulas de Matemática, com os professores parceiros da rede REM-NE e que objetivam discutir elementos locais e globais vinculados à pandemia da Covid-19.

Diante do cenário apresentado, este artigo tem por objetivo analisar práticas colaborativas desenvolvidas, num processo formativo, com professores que ensinam matemática, a partir da metodologia ReflexãoPlanejamento-Ação-Reflexão.

\footnotetext{
${ }^{4} \mathrm{O}$ objetivo geral do projeto foi investigar e intervir na prática de professores do Ensino Fundamental no que tange às Estruturas Multiplicativas, baseados no modelo de formação processo dialético RePARe - Reflexão-PlanejamentoAção-Reflexão (MAGINA, 2008, 2013), tendo em vista a formação de um grupo com características colaborativas.
} 


\section{A pesquisa colaborativa}

Em busca de mudanças nas abordagens metodológicas de ensino, nas últimas décadas, temos observado um aumento de pesquisas que discutem a formação de professores. Isso ocorre porque "não há ensino de qualidade, nem reforma educativa, nem inovação pedagógica, sem uma adequada formação de professores" (NÓVOA, 1997, p. 9). Sob essa ótica, acerca do processo de formação de professores, pautando-se pela colaboração, Ponte (2012) afirma que ela se configura como uma atividade de coprodução dos saberes, de reflexão sobre práticas e de desenvolvimento profissional. Dessa forma, ela se pauta na construção de cenários onde formadores, pesquisadores, interlocutores e professores agem interativamente, de forma a compreender e transformar determinada realidade educativa.

Dito isso, investigações que envolvem pesquisa colaborativa, trabalho colaborativo ou estudo de grupos e práticas colaborativas têm ganhado espaço no cenário educativo, visto que preveem, além da produção de saberes que valorizam a relação entre teoria e prática, a construção de um modelo de formação de professores que supera a perspectiva tradicionalista.

Pensar em pesquisa colaborativa é antes de tudo entender o que é pesquisa-ação. A pesquisa-ação tem o propósito de transformar a escola em um espaço crítico, onde os professores reflitam e reformulem suas práticas, como propõe Ibiapina (2008). Para essa pesquisadora, a pesquisa-ação parte de três condições básicas:

[...] o estudo é desencadeado a partir de determinada prática social susceptível de melhoria; é realizado levando-se em consideração a espiral de planejamento, ação, observação, reflexão, nova ação; é desenvolvido, preferencialmente, de forma colaborativa (IBIAPINA, 2008, p. 9). 
Percebe-se que seu processo consiste em possibilitar a emancipação do professor a partir de reflexões e ações, com vistas a melhorias em sua prática, buscando transformar tanto a sala de aula quanto a escola.

Inspirada em Carr e Kemmins (1988), Ibiapina (2008) apresenta três modelos de pesquisa-ação, sendo eles: Pesquisa-ação Técnica, Pesquisa-ação Prática e Pesquisa-ação Emancipatória. Na primeira, a presença do pesquisador como agente externo é forte, havendo um distanciamento da prática para buscar compreendê-la. Na segunda, o professor pode se transformar em pesquisador de sua prática, mas não há desenvolvimento sistemático que busque a reflexão. $\mathrm{Na}$ terceira, as decisões são tomadas conjuntamente, tendo como um de seus princípios a investigação da própria ação educativa.

Esse último modelo é base para o nosso estudo, pois "a pesquisaação somente pode ser considerada emancipatória quando é colaborativa" (IBIAPINA, 2008, p. 17). Nela, o pesquisador deixa de ser o ator, que fala sobre a Educação, e passa a investigar para a Educação, e o professor deixa de ser apenas objeto e passa a compartilhar com os pesquisadores o ato de transformar sua prática, a escola e a sociedade. Ou seja, as pesquisas deixam de ser sobre os professores e passam a ser com os professores. De acordo com a autora acima citada, ao se desenvolver pesquisa nessa perspectiva, o pesquisador passa a ser aquele que auxilia o professor a analisar e a teorizar sobre a sua prática. É um movimento de construção coletiva, em que não mais o pesquisador apresenta teorias inquestionáveis, mas que em conjunto, a partir da prática, ela se constitui.

Há três condições necessárias para que, de fato, se possa constituir uma pesquisa-ação emancipatória: a colaboração, círculos reflexivos e a coprodução de conhecimentos entre pesquisadores e professores (IBIAPINA, 2008). Inicialmente, vale discutir o significado de colaboração, ressaltando sua distinção da cooperação, visto que, por vezes, são denominações tratadas como sinônimas. Para Ibiapina (2008), cooperação consiste em um trabalho 
coletivo, a partir do qual os envolvidos não possuem autonomia, e as relações de poder são hierárquicas. Na colaboração, a tomada de decisões é democrática, e todos os envolvidos possuem as mesmas oportunidades de apresentarem suas percepções e princípios. Dentro dessa mesma perspectiva, Fiorentini (2013, p. 56) destaca que

[...] na cooperação, uns ajudam os outros ("co-operam"), executando tarefas cujas finalidades geralmente não resultam de negociação conjunta do grupo, podendo haver subserviência de uns em relação aos outros e/ou relações desiguais e hierárquicas. Na colaboração, todos trabalham conjuntamente ("co-laboram") e se apoiam mutuamente, visando atingir objetivos comuns negociados pelo coletivo do grupo.

Assim como é discutido pelos autores, a colaboração é marcada por liderança compartilhada e responsabilidade conjunta pelas ações do grupo. $\mathrm{Na}$ cooperação, diferentemente, há relações de poder entre os membros, as quais geram domínio de uns sobre os outros. Ou seja, tal como aponta Ibiapina, inspirada em Kemmis (1987) e Desgagné (1997), a colaboração implica a negociação dos conflitos existentes no processo de ensino e de aprendizagem, buscando uma ação comum e a comunicação entre pesquisadores e professores, de forma a favorecer as tomadas de decisão.

Sobre os círculos reflexivos, é necessário haver ações sistematizadas de reflexões que possibilitem aos professores pensar sobre as ideias construídas até então sobre o trabalho docente, buscando a construção de práticas que priorizem a criatividade da profissão. Portanto, "refletir sobre a prática envolve tanto a necessidade de rever a teoria quanto de desvelar vicissitudes da ação docente" (IBIAPINA, 2008, p. 18).

Nos pressupostos até agora discutidos, a reflexividade é atividade fundamental na pesquisa colaborativa e, para o desenvolvimento dessa reflexão, são necessários dispositivos mediadores, tais como: entrevistas, vídeo-formação, autobiografia, observação colaborativa e as sessões reflexivas, destacando que todas essas ferramentas, além de gerarem dados de pesquisa, visam ao desenvolvimento profissional e à emancipação docente. 
A coprodução diz respeito ao envolvimento do professor nas atividades de pesquisa, não sendo ele apenas um usuário dos saberes elaborados por terceiros (IBIAPINA, 2008). A autora aponta que esse tipo de pesquisa

[...] é produzida por intermédio das interações estabelecidas entre as múltiplas competências de cada um dos partícipes, os professores, com o potencial de análise das práticas pedagógicas; e o pesquisador, com o potencial de formador e de organizador das etapas formais da pesquisa (IBIAPINA, 2008, p. 20).

Assim, compreende-se que as atribuições dos participantes não são as mesmas, mas são valorizadas as competências de cada um. Por um lado, o professor com a sua prática, e de outro, o pesquisador, enquanto formador, que, em conjunto com o professor, busca compreender essa prática por meio de reflexões, buscando teorizá-la. Esse movimento interativo entre as partes potencializa a qualidade da colaboração. Ancorada em Desgagné (2001), Ibiapina salienta que

Os docentes não necessariamente sejam chamados a participar das tarefas formais de pesquisa como, por exemplo, das etapas de definição do quadro conceitual necessário à problematização aos objetivos de pesquisa, da metodologia de construção e análise de dados e da produção e difusão dos resultados (IBIAPINA, 2008, p. 21).

Essas etapas dizem mais respeito ao pesquisador do que aos professores. A reflexão e a busca pela compreensão da prática estão relacionadas diretamente aos professores, que, com a mediação do pesquisador, as compreenderá a partir de teorias, buscando ressignificálas, bem como serão apresentados a novas situações, de forma a contribuir para o desenvolvimento profissional e a produção de teorias mais próximas dos anseios sociais.

Em uma pesquisa colaborativa, os pesquisadores devem colaborar com professores em seu desenvolvimento profissional, promovendo reflexões acerca da complexidade, que envolve a atividade docente, e os professores colaboram ao refletirem sobre a atividade docente, 
transformando-a, se necessário. Acerca dos papéis do pesquisador e do professor, temos que

[...] quando se fala em pesquisa colaborativa, supõe-se, inicialmente, que os docentes participem de todas as etapas ligadas à investigação formal e, também, que eles sejam responsáveis por delimitar e definir, juntamente com o pesquisador, o objeto de pesquisa, os processos de construção de análise de dados, a apresentação e a publicação dos resultados obtidos com o estudo. De fato, colaborar não significa que todos devam participar das mesmas tarefas e com a mesma intensidade, mas que, sobre a base de um projeto comum, cada partícipe preste sua contribuição específica, isto é, contribua para beneficiar o projeto (IBIAPINA, 2008, p. 31).

Percebe-se, portanto, que esse tipo de investigação envolve um desenvolvimento complexo, que leva tempo para sua compreensão, pois requer aprendizagens múltiplas, envolvendo ações formativas que possibilitem ao professor valorizar o lugar do outro, construção de ambientes de discussão, autonomia e respeito mútuo.

\section{O que apontam estudos com características colaborativas}

Apesar de compreendermos que autores têm apresentado perspectivas distintas acerca da pesquisa colaborativa, propõe-se nesta seção discutir três trabalhos que envolvem esse tipo de investigação ou, pelo menos, possuem elementos dela, a fim de evidenciar características colaborativas.

Curi (2018) discute contribuições de um grupo colaborativo no desenvolvimento profissional de professores. Tal grupo constituiu-se por pesquisadores, estudantes de graduação, professores e bolsistas, tendo seus estudos voltados para o ensino e a aprendizagem de Matemática. A partir das discussões realizadas pela autora, identificam-se algumas características da colaboração nas atividades do grupo que valem ser discutidas. A primeira refere-se ao estabelecimento de objetivos comuns, pois, apesar de envolver profissionais com diferentes experiências e 
trajetórias acadêmicas, os sujeitos selecionam objetivo comum: melhoria do ensino de Matemática.

Outra característica envolve a formação de professores e a produção de conhecimentos acadêmicos pelo grupo - defesas de teses e dissertações. De acordo com a autora, os estudos realizados no grupo favorecem "ampliação de conceitos e procedimentos matemáticos e no conhecimento mais profundo do currículo proposto" (CURI, 2018, p. 47). Tal como se espera desse tipo de processo formativo, baseado na colaboração, o papel do professor é modificado, visto que esse profissional é assumido como pesquisador e produtor de conhecimento. A autora enfatiza tal perspectiva ao apontar que

\begin{abstract}
Neste grupo assumiu-se a postura de que o professor é um sujeito competente e ativo e não um mero aplicador de currículos, ou seja, que o professor vinculado à escola pública também é um pesquisador em educação, protagonista de sua própria prática e desenvolve conhecimentos na ação (CURI, 2018, p. 44).
\end{abstract}

Outra característica identificada, trata-se do estabelecimento da prática como ponto de partida. Tal concepção parte da necessidade de superação da dicotomia teoria e prática, por meio da valorização de conhecimentos advindos da prática educativa, de modo que essa aproximação ocorre por meio da reflexão. A autora revela tal abordagem quando explica que

[...] nas reuniões do grupo, as discussões se iniciavam a partir de reflexões sobre práticas em sala de aula e o desempenho em Matemática dos alunos na Prova Brasil. A partir dessas discussões, os estudos teóricos eram incorporados. Isso permitia relacionar referenciais teóricos e situações da prática, possibilitando reflexões sobre a prática dos professores, promovendo o desenvolvimento profissional (CURI, 2018, p. 47).

Outro grupo colaborativo que vale ser discutido foi desenvolvido a partir de um projeto intitulado "Desafios para a educação inclusiva: pensando a formação de professores sobre os processos de domínio da matemática nas séries iniciais da educação básica”. As contribuições desse 
grupo foram discutidas por Manrique (2018), a qual relata a influência das práticas colaborativas para o desenvolvimento profissional dos partícipes. $\mathrm{Na}$ discussão realizada pela autora, também elencamos algumas características da colaboração no grupo mencionado.

Das características observadas, elencamos a formação de professores e produção de conhecimentos acadêmicos. Tais elementos visam superar um tipo de formação docente abordado por Grecci e Fiorentini (2018): desenvolvimento profissional para a prática. Nesse tipo de concepção formativa, o professor é tido como um mero receptor de conhecimentos e metodologias produzidas pela academia, buscando, em sua atividade docente, reproduzi-las. Esse tipo de abordagem passa a ser refutada, pois o contexto da sala de aula é dinâmico e imprevisível, e o professor pode se deparar com conflitos para os quais não foi preparado. Para tanto, faz-se necessário rever o papel do professor, deixando este de ser um mero reprodutor de conhecimentos, mas um sujeito capaz de refletir, tomar decisões, pesquisar e transformar sua prática docente. Tendo em vista essa concepção, temos que o grupo envolve

Além de reflexões a respeito das condições de trabalho das professoras participantes do grupo colaborativo, nos encontros de formação, ocorriam seminários sobre tipos de deficiências e sobre conteúdos matemáticos, elaboração de atividades, compartilhamento de experiências de sala de aula, preparação de oficinas para serem desenvolvidas nas escolas vinculadas ao projeto, utilização de softwares educativos para o ensino de matemática, entre outras ações formativas (MANRIQUE, 2018, p. 58).

Esse tipo de formação favorece o desenvolvimento profissional crítico de professores e apresenta contribuições diretas nas práticas educativas, tal como apontado pela autora ao afirmar que as mudanças na concepção dos professores acerca do ensino de Matemática acarretaram transformações na prática docente.

Estudo semelhante foi realizado por Gama e Fiorentini (2009) ao investigarem as contribuições de grupos colaborativos na formação de 
professores de Matemática em início de carreira. Esse período inicial da profissão condiz com os primeiros três anos da atividade docente, considerados como uma etapa marcada por sentimentos de "sobrevivência" e "descoberta". A investigação foi realizada com três professores de Matemática do interior de São Paulo, participantes de três grupos distintos ${ }^{5}$, com características colaborativas.

De acordo com Gama e Fiorentini (2009), os grupos pesquisados eram formados por coordenadores de escola, pós-graduandos, licenciandos, professores universitários e escolares dos anos iniciais do Ensino Fundamental e Médio, salientando as diferentes experiências entre os partícipes do grupo. O caráter formativo de professores é evidenciado pelos autores, ao apontarem que

[...] professores desenvolvem, no interior dos grupos, um processo de formação contínua em um paradigma que coloca como centro de preocupação o desenvolvimento profissional dos docentes participantes e a transformação de suas práticas de ensinar e aprender matemática nas escolas (GAMA; FIORENTINI, 2009, p. 447).

Os autores identificaram que as reflexões proporcionadas pelos grupos, as trocas de experiências, os estudos teóricos sobre a aprendizagem de Matemática e a colaboração entre os participantes foram fundamentais na formação dos professores investigados. Os autores evidenciaram que esse período inicial da docência é marcado por inseguranças, e o sentimento de pertencimento em um grupo de profissionais dedicados à melhoria do ensino foram fundamentais para a superação de dificuldades e transformação da prática. Isso pode ser identificado no seguinte excerto:

Pudemos evidenciar que os grupos colaborativos contribuíram para a prática profissional dos professores iniciantes ao promover um processo reflexivo e sistemático (individual e coletivo) sobre a prática docente; por fornecer apoio para enfrentar os desafios e as dificuldades que o

\footnotetext{
${ }^{5}$ Grupo de Sábado (GdS) na Faculdade de Educação da Universidade Estadual de Campinas; Grupo de Educação Matemática (GEM) no Departamento de Metodologia de Ensino da Universidade Federal de São Carlos; Grupo Colaborativo de Estudos em Educação Matemática (GCEEM) na Diretoria Regional de Americana.
} 
professor iniciante encontra diante da complexidade da prática escolar, principalmente porque a ele são geralmente atribuídas às classes mais problemáticas da escola; por promover mudanças da prática pedagógica nas escolas, valorizando a exploração, a problematização e a interação entre os alunos, sobretudo o trabalho em grupo e a socialização inter-grupos e por conduzir os professores a ouvir atentamente os alunos, considerando suas respostas e significações, fazendo intervenções questionadoras, promovendo a negociação de significados e a construção de conceitos matemáticos com seus alunos (GAMA; FIORENTINI, 2009, p. 459).

Percebe-se, portanto, que tais grupos favorecem o desenvolvimento profissional de professores, promovem reflexões acerca da Educação e incentivam mudanças na sala de aula, de forma que a Educação deixa de ser um processo individual e se constitui em uma preocupação coletiva.

\section{Percurso metodológico}

O presente estudo enquadra-se dentro de uma abordagem qualitativa, em consonância com Triviños (1987), tendo em vista que esse tipo de pesquisa tem como característica estudos descritivos os quais necessitam que o pesquisador faça delimitações de técnicas, faça usos de métodos, apoie-se em teorias para conseguir realizar uma coleta e interpretação dos dados, indicando uma separação entre o sujeito que faz as observações e o objeto que está sendo observado, sem ocorrer interferência pessoal, como aponta Bicudo (2012).

$\mathrm{Na}$ direção do que foi dito, o presente estudo discute um pequeno recorte de uma pesquisa em desenvolvimento, que analisa o processo de formação com 28 professores da Educação Básica atuantes nas escolas parceiras de nosso projeto, em uma construção colaborativa sobre atividade de Educação Estatística, que pode repercutir para o desenvolvimento profissional desses professores a partir da pesquisa colaborativa. Esses professores atuam em escolas públicas nos anos iniciais e finais do Ensino Fundamental e são pedagogos ou licenciados em Matemática. 
Todos os professores assinaram o Termo de Consentimento Livre e Esclarecido (TCLE), e, para preservar suas identidades, atribuímos a eles nomes fictícios. O projeto está registrado no Comitê de Ética em Pesquisa (CEP), com o protocolo número 26229119.1.1001.5526 e parecer consubstanciado número 3.813.638/2020.

O processo formativo desenvolvido pela REM-NE pauta-se nos pressupostos teóricos propostos por Day (2001) e Ponte (2012), compreendendo a formação continuada de professores na perspectiva do desenvolvimento profissional, pois segundo Day (2001, p. 233), "a formação contínua é uma área necessária e potencialmente rica do desenvolvimento profissional contínuo dos professores". Nessa direção, a formação envolve o professor em diferentes atividades, como planejamento, reflexão e ação, em atividades coletivas e individuais, cujo foco é a atividade em sala de aula e a aprendizagem dos estudantes envolvidos. A constituição do processo formativo sob essa ótica "é gerado numa movimentação interna e envolve o docente em seus aspectos cognitivos, afetivos e funcionais, tem motivações internas e pode proporcionar a autonomia do professor em sala de aula" (SANTANA et al., 2018, p. 3).

Diante do que foi dito, a condução do processo formativo em investigação sustenta-se no modelo Reflexão-Planejamento-AçãoReflexão (espiral RePARe), proposto por Magina (2008) e readaptado por Magina e colaboradores (2018), conforme Figura 1, que visa promover o desenvolvimento de estratégias de ensino para a apropriação e expansão do campo conceitual em trabalho (no caso deste estudo, o campo conceitual estatístico), por parte dos professores da Educação Básica participantes, de forma semelhante aos estudos desenvolvidos por Magina (2008) e Santana et. al. (2018). 
FIGURA 1: Modelo atual da espiral RePARe

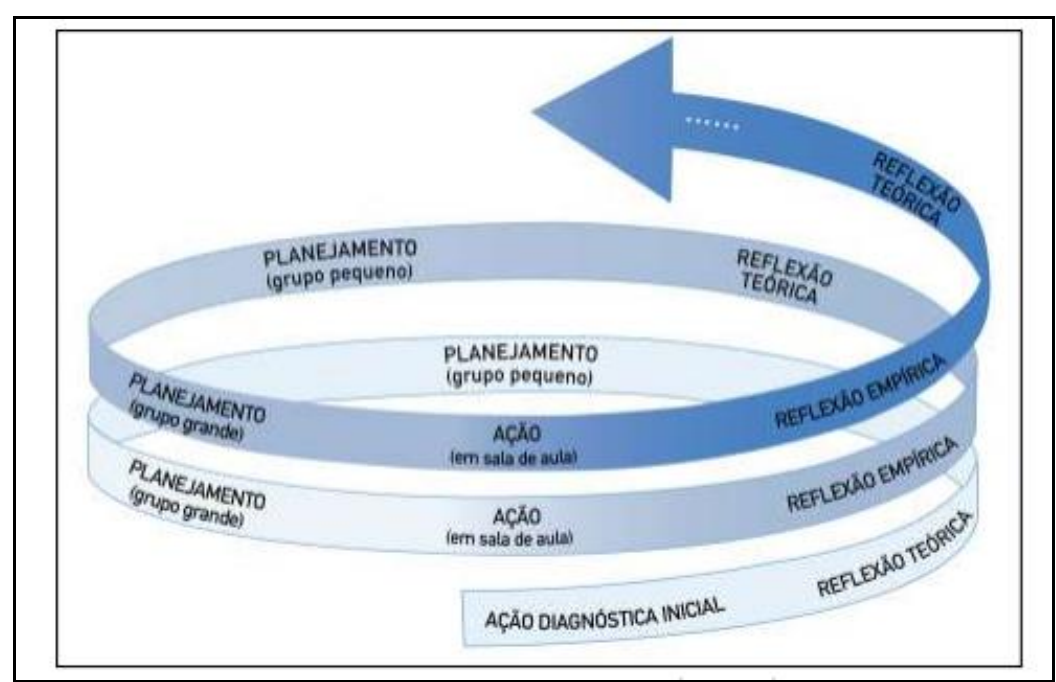

Fonte: MAGINA, SANTANA, SANTOS e MERLINI, 2018, p. 247.

A proposta metodológica desse modelo formativo, como indicado por Magina e colaboradores (2018), tem como base um processo dialético de Reflexão-Planejamento-Ação-Reflexão, formando um movimento espiralar crescente e contínuo, que vai se alargando, em termos de conhecimento, a cada volta percorrida.

Em síntese, a partir da espiral e dos estudos de Magina (2008) e Magina e colaboradores (2018), temos que a ação diagnóstica inicial busca a atuação entre os pesquisadores e professores, de forma que possam compreender o conhecimento dos estudantes acerca do conteúdo matemático que será explorado durante o processo formativo. Ela dará base ao debate sobre a aprendizagem dos estudantes. A reflexão teórica é construída a partir dos resultados da ação diagnóstica inicial, tendo como base o conhecimento didático. O planejamento ocorre num movimento similar ao da reflexão e decorre dos resultados das reflexões (empírica e teórica).

Dando continuidade, a ação é o momento em que são elaboradas as atividades e tarefas que vão ser desenvolvidas nas ações dos professores em sala de aula. Já a reflexão empírica, realizada em grupos Pequenos 
formados preferencialmente pelos professores que atuem num mesmo ano escolar, é feita sobre os resultados da ação em sala de aula que foi desenvolvida pelos professores, resultados de como ocorreram as aprendizagens e dificuldades dos estudantes. Tudo isso fomentado na reflexão teórica, no grupo Grande, que é formado por todos os participantes do grupo colaborativo. E nesse processo, a formação é desenvolvida a partir dos apontamentos feitos pelo grupo Grande, na reflexão empírica, que devem dar base para os novos planejamentos a serem construídos pelos professores e pelo grupo.

O processo formativo discutido nesta pesquisa, constituído a partir do modelo da espiral RePARe, ocorreu entre 08 de setembro e 15 de dezembro de 2020, em datas previamente agendadas e de acordo com a disponibilidade de todos os membros do grupo, sendo organizado e ministrado pelos pesquisadores, tendo a participação ativa dos professores nas discussões e tomadas de decisão.

Em função da pandemia da COVID-19, as atividades aconteceram de forma remota, de maneira síncrona e assíncrona, fazendo uso do Google Meet, Google Classroom, Google Drive, Formulários Google e Telegram. Essas atividades constituíam-se de estudo de textos, realização de atividades, participação em chat de dúvidas, apresentações das atividades desenvolvidas de maneira síncrona. Os estudos eram realizados de maneira assíncrona, antes de cada encontro síncrono.

Nesse período, aconteceram encontros em grupos Grandes, ou seja, numa reunião conjunta em que todos os membros do grupo colaborativo, e em grupos Pequenos, que foram subgrupos por ano escolar, para o estudo e planejamento de sequências de ensino. Essas ações foram organizadas em 4 módulos, que tiveram como vertentes o estudo de conteúdos matemáticos, mais especificamente conceitos estatísticos, a equidade e investigação nas aulas de matemática e a elaboração de sequências de ensino.

Para a produção da coleta de dados deste artigo, em que analisamos Pequenos trechos do processo formativo em momentos síncronos nos grupos 
Grandes, os procedimentos utilizados tiveram como base: as narrativas dos professores, as observações diretas das discussões nas salas virtuais e as gravações de áudio e vídeo nos encontros formativos via Google Meet. Nessa perpectiva, todo material dos encontros foi transcrito de acordo com as datas dos encontros e os grupos constituídos.

Mediante o uso da análise interacional e videográfica (JORDAM; HENDERSON, 1995), um tipo de metodologia de investigação, que tenta aproximar nossa visão à dos sujeitos no momento de interação, buscou-se descrever e entender as formas por meio das quais a colaboração do grupo se constitui no processo formativo, via metodologia Reflexão-PlanejamentoAção-Reflexão, em um determinado contexto que é emergente e contingente. A proposta da análise interacional tem como fonte de estudo as minúcias das interações sociais situadas temporal e espacialmente, em particular, nas interações que emergem de maneira natural.

\section{Análises e discussões}

Analisaremos algumas das reflexões realizadas nos encontros formativos, a partir de trechos das narrativas dos professores e pesquisadores, com base nos pressupostos teóricos da constituição de um grupo colaborativo e de como o movimento da espiral RePARe permeia esse processo. Nos encontros formativos, todos os pesquisadores e estudantes do grupo (graduação, mestrado e doutorado) são denominados de formadores e todos os professores são denominados de participantes.

No primeiro encontro síncrono, em um grupo Grande, via Google Classroom, em que todos os formadores e participantes do grupo estão presentes de forma online, após as apresentações iniciais e toda a discussão sobre o processo formativo, conduzida pela pesquisadora coordenadora do projeto e demais pesquisadores participantes, uma das formadoras responsáveis pela mediação desse encontro solicita aos participantes o preenchimento do "diagnóstico do conhecimento estatístico dos professores", 
uma das atividades necessárias e que faz parte da ação diagnóstica inicial (primeira etapa da espiral RePARe). A coleta foi feita via link de um Formulário Google, disponibilizado via chat na sala do Google Classroom, e alguns formadores do grupo acompanharam a postagem do material fora do ambiente do encontro síncrono. As formadoras que mediaram o encontro deram instruções sobre as postagens, e os demais formadores envolvidos acompanharam as ações do grupo, interagindo com todos, quando necessário. Um diálogo inicial é estabelecido.

Participante Maria (via chat): Não consigo enviar.

Participante Joaquina (via chat): Também não estou conseguindo.

Participante José (via chat): Já tentei enviar várias vezes e não vai, dá erro.

Participante Severina (via chat): O meu também. Por que não entregamos após a aula?

Formadora Josefa: Porque esse é um instrumento da pesquisa e que norteará nossas ações.

Participante Isabel: Não estou conseguindo, também concordo em entregar após a aula, acho que é nervosismo (risos).

Participante Conceição: Não estou conseguindo mandar a foto da questão 1 .

Formadora Josefa: Sugestão do Joaquim, fazer no excel, gravar e adicionar o arquivo gravado.

Formadora Carminha: Conceição envie para o email xxxxx@yyyyy.br e coloque no local um documento em branco.

Formadora Josefa: As fotos podem ser enviadas para o e-mail do xxxxx@yyyyy.br. E não precisa anexar arquivo em branco, porque foi retirada a obrigatoriedade.

(As formadoras Carminha, Antônia e Josefa deram algumas sugestões, e o formulário foi sendo respondido por cada participante. De posse dos formulários respondidos, a palavra foi dada à formadora Josefa).

Formadora Josefa: Então, pelo adiantado da hora, não vamos poder ter a interação que seria, na verdade, o que a gente esperava que tivesse nesse momento. Então, nós precisamos dar início a essa vivência do ciclo investigativo para que vocês consigam realizar as atividades da próxima semana...

Em um movimento de pesquisa-ação, vemos a colaboração e os círculos reflexivos se constituindo entre os participantes e formadores sobre a coleta de dados necessária para o desenvolvimento das etapas 
seguintes: reflexão, planejamento e ação da formação a partir do questionário-base e elemento da diagnose inicial, com a participação ativa de todos os membros do grupo. As decisões buscam diálogo de viés democrático, em que todos os envolvidos possuem as mesmas oportunidades de apresentarem suas percepções, como propõe Ibiapina (2008). Nessa direção, vemos também que a colaboração é marcada por uma liderança compartilhada pela mediação conjunta das formadoras que conduzem o processo e da responsabilidade conjunta pelas ações do grupo, na perspectiva de negociação, corroborando a visão de Fiorentini (2013).

Em continuidade ao encontro do grupo Grande, a partir de elementos da diagnose inicial, as quatro formadoras responsáveis pelas atividades do primeiro módulo constroem e realizam a mediação da reflexão teórica, segunda etapa da espiral metodológica, a partir da análise de conceitos estatísticos presentes na apresentação elaborada por elas, considerando o contexto de vivência do projeto ao qual a formação é vinculada: a Pandemia da Covid-19. Vejamos um trecho das discussões nesse processo.

Formadora Josefa: ... a partir de amanhã até a próxima semana, o tema que a gente escolheu para realizar as atividades é um tema que tá muito presente na vida de todos nós, que é a questão da pandemia. Então, fiz uma pequena contextualização.

(Foi apresentado um slide com tema "A Pandemia". Em seguida, foi mostrado um gráfico que informava o número de mortos por Covid-19 no Brasil).

Formadora Josefa: Se a gente faz uma afirmação e eu apresento para vocês só uma fonte: Organização Mundial da Saúde. A gente espera que o que vai ser apresentado é alguma informação que tem a ver com saúde. Eu apresento essa representação gráfica. Rapidamente, no chat, alguém poderia dizer sobre o que trata esse gráfico.

Participante Joaquim (via chat): Número de óbitos pela Covid. Participante Pedro (via chat): Número de óbitos por Covid no Brasil.

Formadora Ana: Joaquim colocou números de óbitos pela Covid. Pedro, a mesma coisa.

Formadora Josefa: Como você descobriu Joaquim?

Participante Bia (via chat): uma crescente maior e depois uma estabilização do número de mortes.

Formadora Ana: A Bia colocou uma crescente maior e depois uma estabilização do número de mortes. 
Formadora Josefa: Isso. Então, por que a gente consegue identificar que está falando do número de mortes e do número de mortes no Brasil?

Participante Joaquim: Identificamos pelo título.

Formadora Josefa: Porque tem um título. E daí, outros colegas já foram além disso? Além de identificar sobre o que trata esse gráfico, já começaram a fazer análises sobre tendências? Olha, teve um crescimento até julho, agora a gente vê um decréscimo no número de mortes. Então, a gente tem informação que, no Brasil, as mortes começaram a ser contabilizadas em março, dia 17 de março, e até o dia 31 de agosto, somavam 121.385 pessoas que se foram por conta do Covid-19.

(A formadora Josefa deu continuidade à contextualização da situação apresentada e mostrou um estudo realizado pelo Imperial College (Londres), que compara condições de sistemas de saúde de países do primeiro e terceiro mundo; a taxa de mortalidade em lugares sem acessos a recursos de higiene, sem condições para realizar o isolamento social e sem acesso a hospitais).

Pelo diálogo acima, evidencia-se que a reflexividade é uma atividade fundamental na pesquisa colaborativa (IBIAPINA, 2008), promovendo reflexões acerca da complexidade que envolve o trabalho docente na abordagem dos conceitos envolvidos nas atividades escolares. Também fica evidente que a diagnose inicial, quando se solicitou o preenchimento do formulário "diagnóstico do conhecimento estatístico dos professores", é o ponto de partida do processo formativo, realizado colaborativamente, de forma que os dados diagnósticos dão subsídios às reflexões teóricas ao longo de todo o processo formativo, como indicam Magina e colaboradores (2018). Trata-se do que Curi (2018) indica como prática como ponto de partida da formação colaborativa.

$\mathrm{Na}$ direção dos diálogos estabelecidos, as trocas de experiências nos estudos teóricos sobre a aprendizagem de conceitos da Matemática, a colaboração e o apoio mútuo entre os participantes e formadores são fundamentais para a formação matemática e o desenvolvimento profissional dos professores. Isso corrobora com a pesquisa de Gama e Fiorentini (2019), bem como a perspectiva de pesquisa com colaboração, na visão de Fiorentini (2013). 
Em um outro encontro de grupo Grande, dando prosseguimento às atividades do módulo de formação, duas formadoras refletem com os participantes acerca dos planejamentos elaborados nos grupos Pequenos (acompanhados por formadores específicos em cada um desses grupos, com atividades realizadas em intervalos entre as formações nos grupos Grandes). Essa etapa do processo formativo acontece sempre após a reflexão teórica, quando os professores são divididos em grupos Pequenos por critérios, como o ano escolar em que atuam, sendo que, nesse momento, eles irão elaborar atividades sobre o conteúdo que foi visto na reflexão teórica, como aponta Magina e colaboradores (2018). A seguir, trazemos um recorte das discussões desse momento.

Formadora Fátima: ...nós vamos fazer uma breve discussão agora no início, só para fazer um encaminhamento de como nós vamos conduzir o trabalho aqui hoje. E hoje nós iremos trabalhar o planejamento da primeira fase do PPDAC em que nós propomos uma atividade dividida em duas partes. $\mathrm{Na}$ parte 1, individualmente, cada professor ia pensar no tema e escrever um problema. $\mathrm{E}$ isso foi feito, e nós discutimos nos nossos grupos. Daí gerou de todos, foram encaminhados para nós 21 problemas.

Formadora Cristina: Como a Fátima colocou, a palavra agora vai estar com os professores que irão apresentar. Cada grupo tem de 3 a 5 minutos para fazer a sua apresentação da atividade 3 , parte 2 . O que foi discutido nos grupos, como é que se chegou ao consenso, em relação ao tema, ao problema, de acordo com o ciclo investigativo, na primeira fase.

Participante Vilma: (apresenta o grupo e agradece o papel da formadora no grupo Pequeno. O slide de sua apresentação é compartilhado na tela para todo o grupo Grande) ...no primeiro momento, foi feita uma discussão, nós nos reunimos através do Telegram, mas também através do Google Meet com a coordenação da professora Fátima. Nós nos reunimos duas vezes e lá nós apresentamos nosso tema, nosso problema de investigação e de lá nós conversamos e decidimos qual dos temas nós iríamos trabalhar. O objeto de conhecimento, os conceitos estatísticos que nós iremos trabalhar, nós tiramos da BNCC, e aí o objeto de conhecimento vai ser a coleta, classificação, representação de dados referentes às variáveis categóricas por meio de tabelas e gráficos. A habilidade que nós temos aqui é uma habilidade que está na BNCC, realizar pesquisa envolvendo variáveis categóricas em um universo de até 50 elementos, organizar 
os dados coletados, utilizando listas, tabelas simples ou de dupla entrada e representá-los em gráficos de coluna simples, com e sem uso de tecnologias digitais.

Observa-se que, após os grupos Pequenos terem realizado seus planejamentos referentes às atividades a serem desenvoldidas no ciclo investigativo, os participantes são convidados pelos formadores a apresentarem suas produções e visões, para cada um dos grupos e para os demais participantes, promovendo reflexões acerca da complexidade que envolve a atividade docente, como sugere Ibiapina (2008). Nessa direção, novos círculos reflexivos são instituídos, buscando a construção de práticas que priorizem a criatividade da profissão.

Nesse momento, a discussão coletiva aborda o ponto de vista do conteúdo que os professores trazem e sua estrutura lógica, como aponta Magina (2013) e Magina e colaboradores (2018), em que os professores sinalizam para a coprodução colaborativa, realizada nos grupos Pequenos, apontada por Ibiapina (2018) e Fiorentini (2018) como parte do envolvimento do professor na atividade de pesquisa. Nessa direção, esse tipo de atividade num processo formativo favorece o desenvolvimento profissional crítico de professores, corroborando os achados de Gama e Fiorentini (2009).

Sob essa ótica, o compartilhamento de experiências para a sala de aula e as concepções dos professores acerca do ensino de Matemática podem acarretar transformações na prática docente e constituem práticas de um trabalho colaborativo na perspectiva apontada por Manrique (2018).

$\mathrm{Na}$ direção das ações e atividades dos módulos formativos, nos grupos Grandes e pequenos, deu-se continuidade à formação dos professores da Educação Básica, vivenciando-se cada uma das etapas da espiral RePARe. As narrativas dos participantes e formadores giraram em torno da constituição do trabalho colaborativo por todos os membros dos módulos. Isso permeou a necessidade de se continuar a abordagem dos conceitos estatísticos tratados no ensino da matemática escolar, pois os conteúdos precisavam ser consolidados com mais profundidade. 


\section{Considerações Finais}

O processo formativo constituiu-se na construção de ambientes de discussão, autonomia e respeito mútuo (elementos basilares de uma prática colaborativa), além de aprendizagem sobre a produção de saberes que valorizam a relação entre teoria e prática. Isso implica um processo de formação continuada colaborativa que, possivelmente, contribuiu para o desenvolvimento profissional dos professores que atuam nesta pesquisa em rede. Nessa direção, identificamos que as reflexões proporcionadas pelo grupo, as trocas de experiências e a colaboração entre os participantes são fundamentais na formação dos professores investigados.

O processo formativo envolve o professor em diferentes atividades, como reflexão, planejamento e ação, em atividades coletivas (em grupos Grandes e Pequenos) e individuais, cuja essência é a ampliação do campo conceitual em discussão (no caso, conceitos estatísticos) e a construção de atividades matemáticas de forma colaborativa. Assim, compreende-se que as atribuições dos participantes não são as mesmas, sendo valorizadas as competências de cada um deles.

A reflexão acontece em vários momentos: entre professores, entre formadores e entre professores e formadores, que incentivam mudanças para o olhar sobre a sala de aula, de forma que o ensino de Matemática deixe de ser um processo individual e se constitua em uma preocupação coletiva. Isso propicia uma reflexão teórica e empírica, que se constituiu em ações de aprendizagens sobre a prática docente e o desenvolvimento profissional.

No que tange às atividades da formação, compreendemos que as ações que foram desenvolvidas a partir da espiral RePARe propiciam uma reflexiva ampliada, possibilitando aos participantes construir e reconstruir significados quando pensam sobre os conceitos e suas práticas docentes. Portanto, as etapas e o desenvolvimento da espiral podem ser entendidos como uma possibilidade de formação continuada de professores e como prática de grupos com características colaborativas. 


\section{Referências}

BICUDO, M. A pesquisa em educação matemática: a prevalência da abordagem qualitativa. Revista Brasileira de Ensino de Ciência e Tecnologia, v. 5, n. 2, pp. 1526, maio-agosto, 2012. DOI: https://doi.org/10.22476/revcted.v3i2.139.

CARR, W.; KEMMIS, S. Becoming critical. East Sussex, Engalnad: Falmer Press, 1988.

CRECCI, V. M.; FIORENTINI, D. Desenvolvimento profissional em comunidades de aprendizagem docente. Educação em Revista, Belo Horizonte, n. 34, pp. 1-20, 2018. DOI: https://doi.org/10.1590/0102-4698172761.

CURI, E. Pesquisas sobre o ensino e a aprendizagem de matemática e desenvolvimento profissional de professores no âmbito de um grupo colaborativo organizado no programa OBEDUC. In: FERNANDES, F. L. P. et al. Das práticas pedagógicas às políticas públicas em educação: diferentes contextos do trabalho colaborativo na formação de professores que ensinam matemática. Campinas: FE/UNICAMP, 2018, pp. 33-53.

DESGAGNÉ, S. Lê concept de recherche colaborative. I'idée d'um rapprochement entre chercheurs universitaires et praticieres enseignants. Revue des Sciences de L'education, v. 2, n. 23, p. 371-393, 1997.

DESGAGNÉ, S. et al. L'approche collaborative de recherche en education: un rapport nouveau à établir entre recherche et formation. Revue des Sciences de l'Éducation, v. 27, n. 1, p. 33-64, 2001.

DAY, C. Desenvolvimento Profissional de Professores: os desafios da aprendizagem permanente. Porto: Porto Editora, 2001.

FIORENTINI, D. Pesquisar práticas colaborativas ou pesquisar colaborativamente? In: BORBA, M. C.; ARAÚJO, J. L. (org.). Pesquisa qualitativa em educação matemática. Belo Horizonte: Autêntica Editora, 2013.

GAMA, R. P.; FIORENTINI, D. Formação continuada em grupos colaborativos: professores de matemática iniciantes e as aprendizagens da prática profissional. Educação Matemática e Pesquisa: São Paulo, v. 11, n. 2, p. 441-461, 2009. Disponível em: https://revistas.pucsp.br/index.php/emp/article/view/2827/1863. Acesso em: 16 maio 2021.

IBIAPINA, I. M. L. M. Pesquisa Colaborativa: investigação, formação e produção de conhecimentos. Brasília: Líber Livro Editora, 2008.

JORDAM, B.; HENDERSON, A. Interaction Analysis: Foundations and Practice. Journal of the learning sciences, v. 4, n. 1, pp. 39-103, 1995.

KEMMIS, S. Critical Reflection. In: WINDEEN, M. F.; ANDREWS, I. Staff development for school improvement. Philadelphia: Falmer Press, 1987. pp. 73-90. 
MAGINA, S. M. P. (Re)significação das Estruturas Multiplicativas. Projeto de Pesquisa. CNPq: Edital Universal, 2008.

MAGINA, S. M. P.; SANTANA, E. R. dos S.; SANTOS, A. dos; MERLINI, V. L. Espiral RePARe: Um modelo metodológico de formação de professor centrado na sala de aula. REAMEC - Rede Amazônica de Educação em Ciências e Matemática, v. 6, n. 2, p. 238258, 2018. DOI: http://10.26571/REAMEC.a2018.v6.n2.p238-258.i6812.

MANRIQUE, A. L. Desafios para a educação inclusiva: a formação continuada de professores que ensinam matemática em um grupo colaborativo. In: FERNANDES, F. L. P. et al. Das práticas pedagógicas às políticas públicas em educação: diferentes contextos do trabalho colaborativo na formação de professores que ensinam matemática. Campinas: FE/UNICAMP, p. 55-63, 2018.

NÓVOA, A. (Org.). Os professores e a sua formação. Lisboa: Dom Quixote, 1997.

PONTE, J. P. Estudiando el conocimiento y el desarrollo profesional del profesorado de matemáticas. In: N. Planas (Ed.). Educación matemática: teoría, crítica y práctica. Graó, p. 83-98, 2012.

SANTANA, E. R. S.; LAUTERT, S. L.; CASTRO-FILHO, J. A.; SANTOS, E. M. Universidade e Escola Parceiras num Processo Formativo. EM TEIA - Revista de Educação Matemática e Tecnológica Iberoamerica, v. 9, n. 1, pp. 01-18, 2018. DOI: https://doi.org/10.36397/emteia.v9i1.234985.

TRIVIÑOS, A. N. S. Introdução à pesquisa em ciências sociais: a pesquisa qualitativa em educação. São Paulo: Atlas, 1987. 